\title{
Un poco de realismo sobre inconstitucionalidad y derogación
}

\author{
Giovanni Battista Ratti*
}

Recepción:01/07/14

Aceptación: 10/10/14

Resumen: El trabajo reconsidera algunos aspectos teóricos del debate sobre inconstitucionalidad y derogación que fue publicado en el segundo número de esta revista. En particular, intenta defender, desde una perspectiva iusrealista, (1) la viabilidad de la tesis kelseniana de la cláusula alternativa tácita, (2) la plausibilidad de la idea de que las declaraciones de inconstitucionalidad son constitutivas de la invalidez constitucional de una norma legislativa, (3) la tesis según la cual la dicotomía entre orden jurídico depurado y orden jurídico no depurado tiene algunos problemas conceptuales y es de dudosa aplicación a los ordenamientos jurídicos vigentes, (4) la sustancial corrección de las tesis guastinianas sobre las relaciones entre validez formal y validez material, (5) la viabilidad de la tesis, propugnada por diversos autores realistas, de que el derecho controla la admisibilidad de las consecuencias lógicas de las normas promulgadas, así como (6) la necesidad de introducir, en el ámbito del análisis de las relaciones conceptuales entre derogación e inconstitucionalidad, el examen de cómo se maneja, en la práctica jurídica, la situación en la que el criterio cronológico y el criterio jerárquico convergen para dar prevalencia a una norma sobre otra.

Palabras clave: inconstitucionalidad, derogación, validez.

Abstract: This article reconsiders some theoretical issues involved in the debate about unconstitutionality and derogation that has been published in volume number two of Discusiones. In particular,

Profesor de Filosofía del Derecho, Instituto Tarello para la Filosofía del Derecho, Departamento de Derecho, Universidad de Génova, gbratti@unige.it 
this work purports to defend, from a legal realist perspective, (1) the viability of the kelsenian tacit alternative clause, (2) the soundness of the idea that declarations of unconstitutionality are constitutive of the constitutional invalidity of a legislative norm, (3) the thesis according to which the dichotomy between refined and unrefined legal system has some conceptual pitfalls and its application to actual legal systems is dubious, (4) the substantial correctness of the guastinian thesis about the relationship between formal and material validity, (5) the viability of the thesis, advanced by several realist authors, according to which the law controls the admissibility of enact norms' logical consequences, and (6) the urge to introduce, within the analysis of the relationships between derogation and unconstitutionality, an exploration of how, within legal practice, people handle cases in which the chronological criteria and the hierarchical criteria converge in order to give prevalence to one norm over the other.

Key words: unconstitutionality, derogation, validity.

\section{Introducción ${ }^{1}$}

E1 segundo número de esta revista (publicado en 2001) contiene un interesante debate sobre inconstitucionalidad y derogación, originado por un excelente artículo de Claudina Orunesu, Jorge Rodríguez y Germán Sucar (en adelante, ORS) ${ }^{2}$. En el presente "follow-up" no haré una reconstrucción completa de todas las tesis sostenidas en el debate (lo que conllevaría elaborar una entera monografía), sino que tengo la (mucho más modesta) pretensión de retomar y analizar de manera sucinta algunos de los temas propuestos por ORS, aquellos

1 Agradezco a Riccardo Guastini sus útiles observaciones a una versión previa del presente texto.

2 Orunesu, C., Rodríguez, J. L., Sucar, G., "Inconstitucionalidad y derogación", Discusiones, 2, 2001, (citado en lo que sigue como ORS1). En el mismo número de la revista, se encuentra otra contribución de los autores, la cual contiene las réplicas a los críticos, cuyo título es "Reflexiones ulteriores sobre inconstitucionalidad y derogación" (citado en lo que sigue como ORS2). 
Un poco de realismo sobre inconstitucionalidad y derogación

que a mí me parecen los más importantes y los más discutibles desde un punto de vista filosófico.

\title{
II. La naturaleza conceptual de la cláusula alternativa tácita
}

El punto de partida del análisis de ORS es la crítica de la controvertida tesis de la "cláusula alternativa tácita", que Kelsen habría introducido para explicar la posibilidad de que normas jurídicas inválidas pudieran tener efectos jurídicos, a pesar del hecho de que, de acuerdo con Kelsen, validez, existencia y fuerza obligatoria son conceptos equivalentes o, al menos, que denotan conjuntos de normas coextensionales. En la reconstrucción de ORS, según dicha tesis, "toda norma de competencia que atribuye potestad a una autoridad para promulgar nuevas normas con ciertos contenidos incluye una cláusula alternativa tácita que autoriza al órgano en cuestión a promulgar normas con cualquier contenido" (ORS1, 14). Con arreglo a esta reconstrucción, en consecuencia, la tesis de la cláusula alternativa tácita tendría consecuencias desastrosas:

\begin{abstract}
el legislador estaría autorizado a promulgar normas que respeten las restricciones impuestas por la constitución o normas con cualquier contenido, y el juez estaría autorizado a dictar sentencias ajustándose a lo prescripto por las normas generales del sistema o sentencias con cualquier contenido (ibíd.).
\end{abstract}

Haciéndose eco de una conocida literatura ${ }^{3}$, ORS terminan su análisis sosteniendo que aceptar dicha tesis conllevaría el completo derrumbe de la teoría kelseniana, en particular con referencia a la noción de superioridad jerárquica y con la idea de que los jueces no gocen de una discrecionalidad sin límites.

3 El locus classicus es Bulygin, E., "Cognition and Interpretation of Law", en Gianformaggio, L. y Paulson, S. (eds.), Cognition and Interpretation of Law, Torino, Giappichelli, 1995, págs. 16-24. En la literatura más reciente, puede verse Tur, R., "The Alternative Character of the Legal Norm: Kelsen as a Defeasibilist?", en Duarte D'Almeida, L., Gardner, J. y Green, L. (eds.), Kelsen Revisited. New Essays on the Pure Theory of Law, Oxford, Hart, 2013.

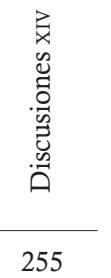


Esta consecuencia es, en mi opinión, demasiado drástica y merece ser rechazada o, más cautelosamente, debilitada.

En relación con la crítica que consiste en sostener que la tesis de la cláusula alternativa tácita cancela la propia idea de la estructura jerárquica del orden jurídico, cabe observar que esto es incorrecto en la medida en que existen otras interpretaciones más caritativas de dicha tesis que consienten salvar la doctrina kelseniana sin renunciar a la tesis bajo cuestión, la cual —es preciso subrayarlo- aparece a lo largo de todo del periodo "clásico" de la obra kelseniana ${ }^{4}$. En particular, lo que Kelsen parece defender es una tesis sustancialmente realista $^{5}$ : una norma es válida ya sea (1) porque ha sido producida de manera regular, o (2) porque no ha sido declarada inválida, a pesar de no haber sido producida regularmente, por una decisión judicial que tiene autoridad de cosa juzgada, o (3) porque ha sido declarada válida, a pesar de no haber sido producida de manera regular, por alguna decisión judicial que tiene autoridad de cosa juzgada ${ }^{6}$.

Leída de esta manera, la cláusula alternativa tácita no es un instrumento para explicar la dinámica jurídica en abstracto, sino para explicar cómo realmente funcionan los sistemas jurídicos en relación con la atribución de validez a las normas. Más allá de esto, la teoría de la cláusula alternativa tácita incluye también una tesis sobre el diseño institucional: si se crea una autoridad que tiene la última palabra sobre las cuestiones relativas a la validez de las normas, entonces debe aceptarse la posibilidad de que dicha autoridad declare válidas normas que no han sido producido regularmente o que colisionan con normas de rango superior ${ }^{7}$. En este sentido, es perfectamente razonable sostener

${ }^{4}$ Kelsen, H., General Theory of Law and State, New Brunswick (NJ), Transaction, [1945] 2006, pág. 153 ss.; ídem, Pure Theory of Law, Berkeley, University of California Press, 1967, pág. 267 ss.

5 Una lectura similar se encuentra en Schmill, U., "Observaciones a Inconstitucionalidad y derogación", Discusiones, 2, 2001, pág. 83.

6 Véase, en la literatura más reciente, Troper, M., "Une théorie réaliste de la validité", Analisi e diritto, 2014.

7 Como es sabido, la (otra) idea central defendida por Kelsen a este respecto es que resulta inútil dictar prohibiciones al legislador sin instituir un tribunal 
Un poco de realismo sobre inconstitucionalidad y derogación

- como lo hace la tesis kelseniana- que una norma es válida si es declarada tal por un órgano que tiene la competencia para hacerlo.

El argumento brindado en contra de esta última tesis por ORS es una referencia a la famosa distinción de Hart entre carácter definitivo y corrección de una sentencia ${ }^{8}$. Así lo formulan los autores marplatenses (ORS1, 19-20):

Una decisión puede ser definitiva, en el sentido que no puede ser cuestionada ante ningún otro órgano $\mathrm{y}$, no obstante, ser equivocada. Los órganos de mayor jerarquía dentro del poder judicial, al resolver las disputas en torno a la inconstitucionalidad de las leyes o la ilegalidad de las sentencias dictadas por otros jueces, pueden tomar decisiones a cuyo respecto no quepa recurso alguno. Pero el carácter definitivo de tales decisiones no les acuerda corrección. Si una norma ha sido dictada en violación de la constitución, eso no cambia por el hecho de que la Corte Suprema rechace un pedido de declaración de inconstitucionalidad. Las pautas de corrección de una decisión judicial son independientes del carácter final o definitivo que pueda tener esa decisión.

Este argumento de origen hartiano no puede ser esgrimido en contra de Kelsen, ni de ningún otro autor, por cuatro razones principales: (1) resulta afectado por una petición de principio, en la medida en que asume que hay respuestas correctas, mientras que debería demostrarlo; (2) la circunstancia de que, de hecho, los jueces de última instancia son libres de (o, mejor, competentes para) declarar válidas o inválidas las normas que consideren no se ve de ninguna manera afectada por la posible "incorrección" de su decisión; (3) más exactamente, la propia idea de que las decisiones jurisdiccionales puedan ser "correctas", en un sentido más ambicioso que el sentido básico de encontrarse en el marco de las decisiones jurídicamente admisibles, no es en absoluto pacífica, ya que presupone asunciones metainterpretativas

constitucional.

8 Hart, H. L. A., The Concept of Law, Oxford, Clarendon, II ed., 1994, pág. 141 ss. 
y metasistematorias muy controvertidas; (4) el término "correcto" y sus derivados son términos valorativos y, en cuanto tales, no deberían aparecer en una teoría genuinamente descriptiva del derecho: la tesis kelseniana del marco de los significados jurídicamente admisibles es una pieza de dicha teoría, mientras que la tesis hartiana de la corrección de las sentencias es una pieza de una doctrina fundamentalmente prescriptiva de la decisión judicial. En este contexto, la tesis de la cláusula alternativa tácita no solo es teóricamente admisible, sino incluso necesaria: en efecto, no se ve cómo se podría explicar de otra manera, desde el punto de vista de la validez jurídica, el hecho común de que los tribunales de última instancia se aparten de los significados admisibles para elegir un nuevo significado, que antes de esa decisión se encontraba fuera del marco de los significados reseñados.

\section{Sobre el carácter constitutivo de la declaración de inconstitucionalidad}

Según ORS, una consecuencia sumamente indeseable de la tesis - sostenida por Kelsen y también por Schmill en el debate aquí comentado- según la cual la declaración de inconstitucionalidad tiene carácter constitutivo sería la de desdibujar por completo la formulación efectiva de las normas. Observan al respecto ORS:

La norma constitucional no dice, por ejemplo, que si el legislador dicta una ley que lesiona el derecho a la información debe decretarse su inconstitucionalidad, sino que reza: "cuando el tribunal competente mediante el procedimiento determinado por el orden jurídico, ha establecido con fuerza de cosa juzgada que determinada ley lesiona el derecho a la información, el tribunal debe decretar su inconstitucionalidad". En otras palabras, la constitución no dice más que lo que los jueces dicen que dice. Esta posición solo es defendible sobre la base de una visión radicalmente indeterminista respecto de la interpretación de las normas constitucionales, y lleva a que el control de constitucionalidad no sea más que una suerte de poder de veto de los jueces sobre las normas que dicte 
Un poco de realismo sobre inconstitucionalidad y derogación

el legislador. Si se rechaza esta postura extrema respecto de la interpretación de las normas constitucionales, si se admite que puede haber casos claros de inconstitucionalidad, la conclusión es inadmisible (ORS 2, 142-143).

A mí me parece que aquí los autores están confundiendo dos cuestiones manifiestamente distintas: el carácter definitivo de algunas sentencias (que es un problema relativo a la estructura de los órdenes jurídicos) con las diversas concepciones de la interpretación (que es un problema genuinamente meta-interpretativo).

Antes que nada, encontramos la tesis de que la declaración de inconstitucionalidad es competencia de algunos órganos judiciales determinados. Evidentemente, esta no es una tesis meta-interpretativa en sentido estricto, i.e. no presupone una particular teoría de la interpretación. Se podría abstractamente concebir un caso claro de conflicto entre una cierta lectura de las disposiciones de ley y una cierta lectura de las disposiciones constitucionales, y admitir que otras interpretaciones de las disposiciones involucradas en el proceso argumentativo puedan difícilmente ser propuestas, pero esto no afectaría el hecho de que el órgano judicial de última instancia pueda rechazar que exista dicho conflicto y entonces rehúse identificar un caso de inconstitucionalidad. Asimismo, se puede identificar un conflicto allí donde, a una lectura prima facie de los textos, no parecería haberlo. Mas en general, aunque en el supuesto totalmente académico de que todos los casos fueran interpretativamente claros, el poder otorgado a un órgano judicial de última instancia de decidir sobre la constitucionalidad de las normas legisladas le permite juzgar prescindiendo de la respuesta supuestamente clara.

En efecto, ORS, para poder sostener su división entre inconstitucionalidad y declaración de inconstitucionalidad, presuponen dos tesis harto complicadas para defender: (a) la presencia, en la mayoría de las cuestiones interpretativas, de respuestas correctas, $(b)$ el deber por parte de los jueces de última instancia de ceñirse al significado "correcto" de las disposiciones.

Por lo que puedo ver, la tesis ( $a$ ) es sustentada recurriendo al argumento falaz según el cual, si así no fuera, el derecho no tendría sentido 
como conjunto de pautas que "pretenden" guiar la conducta humana. La tesis $(b)$ presenta valores de verdad contingentes (que dependen de cuál sea la disciplina legal de la interpretación o de la práctica interpretativa de los juristas $)^{9}$. Como es sabido, la disciplina legal de la interpretación en nuestros ordenamientos jurídicos admite - normalmente- muchos cánones interpretativos, de forma que resulta complicado sostener que existe una única interpretación correcta. Esta circunstancia es agravada por el hecho de que la práctica interpretativa -y creativa, sobre todo- de los juristas parece ir mucho más allá de las técnicas explícitamente permitidas por las normas que versan sobre la interpretación de las disposiciones jurídicas.

Más allá de esto, las cortes constitucionales son perfectamente conscientes del poder que les otorgan los documentos constitucionales en tema de interpretación y aplicación del derecho y, en consecuencia, de declaración de inconstitucionalidad de la ley. En particular, como de ellos depende la última palabra sobre la interpretación de la constitución y sobre la interpretación conforme de la ley, parece haber pocas dudas acerca de que es inconstitucional lo que los jueces constitucionales califican de esta manera. Considérese, entre muchos, el ejemplo paradigmático de lo que dispone al respecto la sentencia C-539/11 del Tribunal Constitucional de Colombia:

La jurisprudencia constitucional ha precisado que, dado que todas las autoridades se encuentran sometidas al "imperio de la ley" lo cual significa por sobre todo al imperio de la Constitución, de conformidad con los artículos 2 y 4 Superiores, (i) la tarea de interpretación constitucional no es tarea reservada a las autoridades judiciales, y (ii) que dicha interpretación y aplicación de la ley y de la Constitución debe realizarse conforme a los criterios determinados por el máximo tribunal competente para interpretar y fijar el contenido y alcance de los preceptos de la Constitución. Esta obligación, por parte de las autoridades administrativas de interpretar y

9 La lectura propuesta en el texto es una interpretación caritativa: probablemente, la tesis en cuestión es decididamente prescriptiva y por ende carece de valores de verdad. 
Un poco de realismo sobre inconstitucionalidad y derogación

aplicar las normas a los casos en concreto de conformidad con la Constitución y con el precedente judicial constitucional fijado por esta Corporación, ha sido reiterada en múltiples oportunidades por esta Sala, poniendo de relieve el deber de las autoridades administrativas de ir más allá de las normas de inferior jerarquía para aplicar principios, valores y derechos constitucionales, y de aplicarlos en aras de protegerlos y garantizarlos. En relación con los parámetros de interpretación constitucional para la administración, la jurisprudencia de esta Corporación ha establecido que (i) la Constitución es la norma de normas, (ii) su interpretación definitiva corresponde a la Corte Constitucional, de conformidad con el art. 241 Superior, (iii) que por tanto al ser la guardiana de la integridad y supremacía de la Constitución, la interpretación que haga de ella es vinculante para todos los operadores jurídicos, administrativos o judiciales; y (iv) que el nivel de vinculatoriedad del precedente judicial es absoluto en el caso de las autoridades administrativas, quienes no gozan de la autonomía que le corresponde a los jueces.

A este respecto ha dicho la Corte:

La Constitución Política es una norma. Por lo mismo, su aplicación y respeto obliga a un constante ejercicio hermenéutico para establecer su sentido normativo. La función definitiva en esta materia corresponde a la Corte Constitucional, conforme se desprende del artículo 241 de la Constitución. Así, al ser guardiana de la supremacía e integridad de la Carta, la interpretación que la Corte haga del texto constitucional es vinculante para todos los operadores jurídicos, sea la administración o los jueces.

En suma, en relación con la obligatoriedad y alcance de la doctrina constitucional, la jurisprudencia de esta Corte ha aclarado que esta deviene de que la Constitución es norma de normas, y el precedente constitucional sentado por la Corte Constitucional como guardiana de la supremacía de la Carta tiene fuerza vinculante no solo para la interpretación de la Constitución, sino también para la interpretación de las leyes que obviamente debe hacerse de conformidad con la Carta, 
por eso, las sentencias de la Corte Constitucional constituyen para las autoridades administrativas una fuente obligatoria de derecho.

\section{Dos modelos de orden jurídico}

Otro punto muy relevante en el planteamiento de ORS es la distinción entre dos modelos de orden jurídico que llaman, respectivamente, del orden jurídico depurado y del orden jurídico no depurado.\}

Según el primer modelo,

una de las condiciones de legalidad que debe satisfacer un acto de promulgación para permitir asociar un nuevo sistema al orden jurídico es que la norma o conjunto de normas promulgadas no resulten incompatibles con normas emanadas de un órgano jerárquicamente superior (ORS1, 37).

En dicho modelo, por consiguiente, en ninguno de los sistemas que conforman el orden jurídico existen inconsistencias entre normas dictadas por órganos de diferente jerarquía. El criterio de la lex superior actuaría ex ante, como un criterio que permite bloquear de antemano la entrada al sistema de aquellas normas en conflicto con normas superiores.

En cambio, de acuerdo con el segundo modelo, del orden no depurado, "todo acto de promulgación de una norma produce el ingreso de un nuevo sistema en la secuencia siempre que se satisfagan las condiciones formales relativas al órgano competente y al procedimiento debido" (ORS1, 37). El criterio de la lex superior actuaría ex post, como instrumento para restablecer la consistencia del sistema.

Esta división puede ser criticada al menos por tres razones ${ }^{10}$.

(1) En primer lugar, la propia denominación de los dos modelos propuesta por ORS parece desafortunada. Si un cierto ordenamiento jurídico es libre de inconsistencias por definición, porque en su ámbito

${ }^{10}$ Otras reflexiones críticas se encuentran en Ratti, G. B., "Tres disyuntivas teóricas en la reconstrucción de los órdenes jurídicos", Analisi e diritto, 2013, págs. 61-63. 
Un poco de realismo sobre inconstitucionalidad y derogación

el criterio jerárquico funciona como instrumento para establecer la introducción de nuevas normas, parecería más razonable llamarlo "orden puro", ya que nace sin inconsistencias, y no es depurado por algún operador después de que haya sido creado. Es más, es el segundo modelo el que debería recibir el rótulo de "depurado", justamente porque el criterio jerárquico funciona como un instrumento para restablecer la consistencia, i.e. para depurar el sistema de estas imperfecciones sistemáticas. Evidentemente, este es un punto menor, de mero tenor terminológico, pero quizá esconda alguna confusión sobre el carácter meta-doctrinal, en lugar de simplemente estructural, que convendría asignarle a la dicotomía.

(2) Una segunda crítica a la disyuntiva en cuestión - expresamente formulada por Guastini en el debate bajo examen ${ }^{11}$ — es la siguiente: dicha distinción parece ser más una herramienta para reconstruir los sistemas de control judicial sobre las normas inconstitucionales que un instrumento para explicar cómo funciona la validez jurídica de las normas en relación con diversas lecturas del criterio de la lex superior. $\mathrm{Su}$ éxito, en consecuencia, depende no tanto de las repercusiones teóricas que tengan ambos modelos, sino de la fidelidad con la cual ellos reconstruyen lo que ocurre en los distintos órdenes jurídicos, según el diseño institucional que les subyace.

${ }^{11}$ Guastini, R., "Cinco observaciones sobre validez y derogación", Discusiones, 2, 2001, pág. 61, escribe: "a mí me parece que los dos modelos dependen [...] de dos diversos modos de organizar el control jurisdiccional de constitucionalidad y de legalidad de las normas. En casi todos los ordenamientos contemporáneos el control de constitucionalidad de las leyes y el control de legalidad de los reglamentos [...] se cumplen a posteriori. $\mathrm{Y}$ esto quiere decir, justamente, que las normas (y decisiones individuales) inválidas pueden ingresar en el orden y están destinadas a permanecer en él en tanto no sean anuladas. La mayor parte de los ordenamientos jurídicos contemporáneos se corresponde en consecuencia con el modelo del orden no depurado. Y quien prefiriese describirlos a la luz del modelo del orden jurídico depurado ofrecería una representación engañosa. El modelo del orden depurado solo podría ser útil para describir ordenamientos en los cuales todos los controles de constitucionalidad y legalidad se ejercitasen $a$ priori (y, en verdad, sobre todas las normas)". 
(3) Una tercera perplejidad concierne a las relaciones entre competencia normativa y ambos modelos de órdenes. Los autores marplatenses (ORS1, 37) defienden la tesis según la cual el modelo del orden depurado incorporaría el respeto del principio lex superior en el mismo concepto de competencia, "de forma que no podamos decir que [una cierta autoridad normativa] ha actuado como un órgano competente cuando la norma dictada es incompatible con normas superiores"12. Ahora esto muestra la naturaleza engañosa de dicho modelo, ya que ningún jurista consideraría que un legislador es incompetente, sic et simpliciter, para dictar normas contrarias a la constitución, justamente porque el juicio de inconstitucionalidad es un juicio interpretativo y la inconstitucionalidad es una variable de la interpretación, de forma que deberíamos decir que el legislador es competente para dictar disposiciones normativas, y solo cuando una disposición normativa es considerada incapaz de expresar al menos una norma compatible con las normas constitucionales, entonces se la elimina del orden jurídico.

Que dicha tesis no sea persuasiva lo muestra también el hecho de que el propio Rodríguez haya modificado su postura al respecto en un reciente libro escrito con Jordi Ferrer ${ }^{13}$. Junto con Ferrer, Rodríguez mantiene que la competencia es una propiedad disposicional institucional consistente en la capacidad de producir actos jurídicos válidos ${ }^{14}$. Esta tesis haría posible sostener que un órgano tiene competencia para dictar normas válidas, y que, no obstante, la actualización de dicha competencia depende del cumplimiento de algunas condiciones adicionales, entre las que puede encontrarse la conformidad con el principio lex superior. Esto tendría la consecuencia

${ }^{12}$ Ferrer Beltrán, J. y Rodríguez, J. L. (2011), Jerarquías normativas y dinámica de los sistemas jurídicos, Madrid, Marcial Pons, pág. 175.

${ }^{13}$ Ferrer Beltrán, J. y Rodríguez, J. L., Jerarquías normativas y dinámica de los sistemas jurídicos, cit. Este volumen ha sido debatido en la primera parte del número de 2013 de la revista Analisi e diritto, con contribuciones de Chiassoni, Canale, Moreso, Ratti, Tuzet y Zorzetto. Ferrer y Rodríguez han replicado con el trabajo "Sobre dinámica jurídica y jerarquías normativas: Algunas respuestas a los críticos", Analisi e diritto, 2013, págs. 95-131.

${ }^{14}$ Ferrer Beltrán, J. y Rodríguez, J. L., Jerarquías normativas y dinámica de los sistemas jurídicos, cit., pág. 175 
Un poco de realismo sobre inconstitucionalidad y derogación

muy relevante de permitir distinguir entre una norma dictada por un órgano competente que haya actuado en una situación en la que no se han dado todas las condiciones para la actualización de dicha competencia, y la norma dictada por un conjunto de sujetos carentes de cualquier competencia. Sin embargo, la noción de competencia como propiedad disposicional, al resolver el problema teórico mencionado, parece crear otro más relevante: en ambos modelos de orden (depurado y no) el órgano competente tiene el poder de dictar prescripciones que entran a integrar un cierto sistema, a pesar de ser inválidas, ya que es posible "distinguir la competencia del órgano de las condiciones de validez de las normas por él creadas"15 (ibíd.). Y esto convierte la distinción entre ambos modelos en una muy dudosa en el plano conceptual, aunque pueda tener alguna relevancia - como se dijo- respecto de la descripción de lo que ocurre con los sistemas de control de constitucionalidad que de hecho se dan.

Sin embargo, ORS se oponen a esta última lectura ${ }^{16}$ afirmando que

no es esa la distinción [entre modelos vigentes de control de constitucionalidad] que propusimos. Como se ha expresado, intentamos diferenciar claramente entre la inconstitucionalidad de una norma y la declaración de su inconstitucionalidad. Un pronunciamiento sobre la inconstitucionalidad de una norma solo contingentemente tiene incidencia sobre la pertenencia de una norma a un sistema jurídico. Por consiguiente, ambas cuestiones no deberían ser confundidas. En otras palabras, ambos modelos de reconstrucción de los ordenamientos jurídicos resultan independientes de los mecanismos de control instrumentados. La utilidad de nuestra distinción puede considerarse un punto pendiente de demostración, pero su finalidad es distinta de la lectura que ofrece Guastini (ORS2, 148).

\section{${ }^{15}$ Ibídem.}

${ }^{16}$ Esta oposición ha sido reiterada recientemente en Ferrer Beltrán, J. y Rodríguez, J. L., "Sobre dinámica jurídica y jerarquías normativas: Algunas respuestas a los críticos", op. cit., pág. 117, donde se afirma: "la distinción teórica es enteramente independiente de las concretas configuraciones de los sistemas jurídicos". 
No obstante, planteada así la cuestión parece claro que el modelo del orden jurídico depurado no es vigente virtualmente en ningún sistema jurídico, mientras que la gran mayoría de los ordenamientos asume alguna variante del modelo del orden no depurado. La utilidad de la dicotomía, pues bien, no queda solo pendiente de ser demostrada, sino que, desde esta perspectiva, queda totalmente en entredicho ${ }^{17}$.

\section{Validez formal y validez material}

Uno de los puntos más interesantes de la contribución de ORS se encuentra en el intento de los autores de usar instrumentos guastinianos para sostener que Guastini se equivoca respecto a las relaciones entre validez e invalidez formal y material.

ORS parten de la conocida tesis según la cual un sistema jurídico estaría compuesto por un conjunto de normas expresamente promulgadas y por un conjunto de normas que, si bien no han sido expresamente promulgadas, son admitidas en el sistema jurídico por derivarse lógicamente de las primeras. Las condiciones de pertenencia al sistema de estos dos conjuntos de normas - observan los autores marplatenses (ORS1, 26-27) — son diferentes:

las normas promulgadas se consideran parte de él si el acto de su promulgación se encuentra autorizado por normas del sistema (criterio de legalidad); las normas no promulgadas pertenecen al sistema si son consecuencias lógicas de las normas que integran el sistema (criterio de deducibilidad).

De esto, a su vez, se deriva que

${ }^{17}$ Esta cuestión reaparece también en la discusión que ORS tienen con Pablo Perot, al responder a las observaciones críticas vertidas por Perot en el artículo "Inconstitucionalidad, legalidad y orden jurídico", en el mismo número de la revista. Véase la respuesta de los autores en ORS 2, págs. 146-147. Véase también, en la literatura más reciente, Ferrer Beltrán, J. y Rodríguez, J. L., "Sobre dinámica jurídica y jerarquías normativas: Algunas respuestas a los críticos”, op. cit., págs. 116-117. 
Un poco de realismo sobre inconstitucionalidad y derogación

aún cuando en algún sentido al menos derivado pudiera predicarse "validez formal" de las normas expresamente promulgadas, parece claro que esa calificación no puede aplicarse a las normas no promulgadas, ya que con la expresión "validez formal" se hace referencia a la regularidad del acto de promulgación, la cual obviamente no puede tener incidencia alguna respecto de la pertenencia al sistema de una norma que no ha sido promulgada. En consecuencia, las normas no promulgadas no son ni válidas ni inválidas desde el punto de vista formal.

Según ORS, Guastini se opondría a estas tesis sosteniendo que en caso de conflicto entre ambos, el criterio material prevalece sobre el formal: por así decirlo, la validez material es "más fuerte" que la validez formal. En consecuencia, si una norma es válida tanto en sentido formal como en sentido material, no hay problemas. Sin embargo, (a) una norma formulada, aunque sea formalmente válida, es no obstante considerada inválida si resulta inconsistente con normas de jerarquía superior; (b) una norma no formulada, aunque sea formalmente inválida, es no obstante considerada válida siempre que pueda ser convincentemente derivada a partir de alguna norma formulada (formalmente válida).

Pues bien, las críticas a esta tesis de Guastini propuestas por los autores marplatenses son esencialmente dos (ORS1, 26 ss.).

(1) Validez formal y validez material son predicados de entidades diferentes (la primera es un predicado de disposiciones normativas; la segunda de normas), entonces no tiene sentido - como parece hacerlo Guastini- decir que una de ellas prevalece sobre la otra.

(2) Las condiciones de validez de normas promulgadas y de normas no promulgadas son diferentes, de forma que no puede calificarse como inválida a una norma no promulgada porque no satisface una condición de validez (como es, verbigracia, la regularidad formal) que es propia de las normas promulgadas (que no son otra cosa que significados de disposiciones normativas).

De ahí que, para ORS, no tenga sentido sostener que la validez material sea más fuerte que la validez formal. 
Las críticas de ORS no me persuaden totalmente, por dos razones principales. Primero, cabe observar que las normas derivadas, en cuanto parasitarias respecto de las normas promulgadas, dependen, aunque indirectamente, de la validez de aquellas, de forma que si una cierta disposición $\mathrm{D}$ es formalmente inválida, esto hace inválidas también las normas que se desprenden de ella por interpretación y, con mayor razón, las que derivan lógicamente de ellas (asumiendo, obviamente, que no puedan ser derivadas lógicamente de otras normas formalmente válidas).

Segundo, si se analizan las normas derivadas en aislamiento, cabe observar que ellas no forman parte de las normas formalmente válidas (es decir, son formalmente no-válidas), pero forman parte del conjunto de las normas materialmente válidas. Este último conjunto es formado también por las normas materialmente válidas que, además, son también formalmente válidas (por proceder de actos normativos regulares). Si esto - como creo- es correcto, hay una justificación para lo que sostiene Guastini: el conjunto de las normas materialmente válidas es más amplio que el de las normas formalmente válidas. Puede que Guastini no haya distinguido, en esta ocasión, entre normas formalmente inválidas (es decir, normas que no reúnen las condiciones para ser consideradas formalmente válidas, a pesar de que "deberían" hacerlo) y normas formalmente no-válidas (es decir, normas de las que no se requiere, de por sí, producción regular), pero esto no autoriza - entiendo - a descalificar su tesis como carente de fundamentación.

\section{La derogación de normas implícitas}

Siguiendo a Alchourrón y Bulygin, ORS sostiene que, cuando una norma derivada es derogada (mediante una regla tácitamente derogatoria, como por ejemplo "Todas las normas que entren en conflicto con esta ley serán derogadas", o simplemente aplicando el criterio lex posterior), no es siempre cierto que el resultado de tal acto derogatorio sea un sistema bien formado. No solo es necesario, de hecho, derogar la norma derivada, sino también aquellas normas que implican tal 
Un poco de realismo sobre inconstitucionalidad y derogación

norma derivada (al igual que aquellas normas que son consecuencia lógica de la norma derivada). En otras palabras, la derogación tiene un efecto "de arriba hacia abajo" sobre las reglas implicadas, y un efecto "de abajo hacia arriba" sobre la reglas "implicantes".

En este marco, puede ocurrir que, de cara a derogar una cierta norma derivada, dos normas expresas puedan ser alternativamente derogadas (siendo innecesario derogar ambas). En tal circunstancia, el resultado de la derogación no es un sistema normativo determinado, sino al menos dos sistemas normativos alternativos.

La demostración formal reza como sigue ${ }^{18}$. Supongamos que tenemos un sistema formado por las siguientes normas:

N1: $(\sim \mathrm{O} \sim \mathrm{p} \& \sim \mathrm{O} \sim \mathrm{q}) \supset \sim \mathrm{O} \sim \mathrm{r}$

N2: Op

N3: Oq

Tal y como resulta sencillo ver, las normas N2 y N3 implican la norma $\mathrm{N} 4$ " $\sim \mathrm{O} \sim \mathrm{p} \& \sim \mathrm{O} \sim \mathrm{q}$ "19. La norma $\mathrm{N} 4$, a su vez, implica, junto con N1, la norma N5: " O r r". Si uno quiere derogar la norma derivada N5 (algo que sólo puede ser hecho tácitamente a través de una regla derogatoria general), tal agente puede cancelar la norma $\mathrm{N} 2$ o la norma N3 (o ambas, aunque esto parece innecesario), pero no hay razón lógica para preferir la derogación de alguna de tales normas. Esta circunstancia afecta a la unidad de un sistema normativo, ya que lo descompone en sistemas normativos alternativos. El efecto de la derogación (tácita) de la norma derivada N5 no es, en este caso, un sistema bien formado, sino más bien el de varios conjuntos de normas.

${ }^{18}$ Aquí me apoyo, en particular, en Alchourrón, C. E. y Bulygin, E., "Sobre el concepto de orden jurídico" (1976), en Alchourrón, C. E. y Bulygin, E., Análisis lógico y derecho, Madrid, Centro de estudios constitucionales, 1991, págs. 401-404.

${ }^{19}$ Recuérdese que, para la lógica deóntica de Alchourrón y Bulygin (y virtualmente para todos los sistemas de lógica deóntica), de hecho, Op implica $\sim \mathrm{O} \sim \mathrm{p}$ (esto es, obligatorio implica permitido). 
Esta tesis ha sido impugnada por Guastini en el debate que estamos analizando.

La idea de Guastini es que la demostración es errónea, ya que no da cuenta de un elemento distintivo de la lógica jurídica: "el razonamiento jurídico está gobernado no solo por la lógica, sino por el propio derecho. En el sentido de que es posible que el derecho excluya la admisibilidad de algunas inferencias que son lógicamente válidas" y el derecho admite algunas inferencias que son lógicamente inválidas ${ }^{20}$. Guastini también afirma que, si uno puede derivar lógicamente una cierta norma (c) a partir de las normas expresas (a) y (b), pero la norma (c) entra en conflicto con la norma expresa (d), promulgada después de (a) y (b), entonces (c) no es la conclusión de una inferencia jurídicamente admisible (pese a que es aceptable desde un punto de vista deductivo $)^{21}$. Hasta la promulgación de (d), el sistema jurídico incluía las normas (a), (b) y (c). A partir de la promulgación de (d) y en adelante, el sistema incluirá las normas (a), (b) y (d).

A esta tesis, ORS replican sosteniendo que la tesis de Guastini es sustancialmente correcta, pero que es preciso enfatizar las diversas consecuencias que se siguen de cada una de estas dos reconstrucciones. De acuerdo con la de ORS, "es menester aceptar que la promulgación de una norma puede provocar la derogación de otra que no es directamente incompatible con la nueva norma promulgada". En cambio, si se acepta la postura de Guastini, "ello no ocurre, pero es necesario admitir que la promulgación de una norma pueda tener repercusión sobre las reglas de inferencia admisibles en el sistema considerado" (ORS2, 149). Además de esto, la tesis sostenida por Guastini conlleva que si formas de razonamiento lógicamente inválidas (como, por ejemplo, la analogía) son admitidas en ciertos sistemas jurídicos como forma de inferencia (jurídicamente) válida, entonces es necesario "aceptar que en tales sistemas jurídicos podrían

\footnotetext{
${ }^{20}$ Guastini, R., "Cinco observaciones sobre validez y derogación", op. cit., págs. 62-63.

${ }^{21}$ Guastini, R., "Cinco observaciones sobre validez y derogación", op. cit., pág. 63.
} 
Un poco de realismo sobre inconstitucionalidad y derogación

derivarse consecuencias contradictorias incluso para los casos consistentemente normados" (ORS2, 148).

ORS sostienen que el hecho de que las autoridades normativas admitan formas inválidas de razonamiento en algunos casos (por ejemplo, la analogía en el caso de lagunas normativas), esto no quiere decir que admitan inferencias inválidas como medio para derivar las consecuencias lógicas de las normas. Dicho de otro modo, "puede admitirse la analogía en el derecho sin aceptar que ella constituya una forma de inferencia que permita derivar consecuencias a partir de las normas promulgadas" (ORS 2, 148).

Pese a que esto a ORS les parezca lógicamente descabellado, hay varios sistemas jurídicos donde la analogía es utilizada, de hecho, como un instrumento para derivar (al menos algunas de las) consecuencias lógicas de las normas. Es verdad que muchos de los sistemas jurídicos prevén que la analogía y otros razonamientos "productores" de normas funcionan primariamente como instrumentos para llenar lagunas. Sin embargo, es interesante observar que dichos razonamientos son a menudo usados por los juristas fuera del ámbito previsto por las normas de derecho positivo (i.e. integración de lagunas normativas), originando así inconsistencias ${ }^{22}$. Efectivamente, si se aplica la analogía a un caso regulado por una solución jurídica, lo que se crea es o bien una redundancia (si se usa una determinada ratio para iterar la solución que ya existe) o bien una antinomia (si se usa la ratio para derivar una norma que contradice la que ya existe).

Afirma, por ejemplo, un insigne jurista italiano que

una interpretación constitucionalmente orientada de la materia de la propiedad debe, antes de nada, permitir una aplicación analógica de aquellas normas, las cuales, aunque contradigan el libre desarrollo de las facultades del propietario, constituyen un elemento estructural relativo a la forma de ser de ese tipo de propiedad privada ${ }^{23}$.

${ }^{22}$ Véase Ross, A., On Law and Justice, London, Stevens \& Sons, 1958, pág. 150.

${ }^{23}$ Gambaro, A., Il diritto di proprietà, Milano, Giuffrè, 1995, pág. 47. 
Lo que equivale a decir que la aplicación analógica de algunas normas que limitan los derechos de propiedad debe ser realizada a la luz del dictado constitucional, aunque esto produzca contradicciones en el seno del sistema de la propiedad, ya que dichas situaciones de conflicto pueden ser solucionadas otorgándole primacía a la "función social" de la institución propietaria ${ }^{24}$.

En resumidas cuentas, ORS parecen pasar por alto que según los criterios de identificación usados normalmente por los juristas no siempre las normas derivadas se limitan a aquellas que se desprenden de la aplicación de los criterios de la lógica deductiva. Al contrario, es una cuestión dogmática — que cambia en los diversos órdenes jurídicos- establecer cuáles son los criterios para determinar la pertenencia (y/o la aplicabilidad) de las normas derivadas a (en) un cierto sistema de normas ${ }^{25}$. La confusión entre lo que debería pasar en un sistema normativo ideal con lo que ocurre en los sistemas jurídicos reales es algo frecuente en la literatura positivista de índole no realista, pero es sorprendente que en esta confusión incurran pensadores tan agudos como ORS. En particular, el argumento según el cual si un cierto sistema jurídico admite como jurídicamente válidas formas de razonamiento lógicamente inválidas, entonces se sigue que en tales sistemas jurídicos podrían derivarse consecuencias contradictorias, y por esto no se puede afirmar razonablemente que tales razonamientos "ampliativos" sean instrumentos para derivar las consecuencias lógicas de las normas, constituye una clara petición de principio, en la medida en que sostiene que algo no puede ocurrir bajo la asunción de que un sistema normativo tiene que tener la propiedad de ser racional (en la medida en que admitir razonamientos ampliativos entre las

${ }^{24} \mathrm{Al}$ respecto, Rescigno, P., "La proprietà (dir. priv.)", en Enciclopedia del diritto, XXXVII, Milano, Giuffrè, 1988, pág. 275, habla de «estensibilità analogica delle norme di carattere eccezionale destinate a realizzare la funzione sociale».

${ }^{25}$ Esta pluralidad de modelos es reflejada por las diferentes reconstrucciones teóricas correspondientes. Véase Ferrer Beltrán, J. y Ratti, G. B., "Validity and Defeasibility in the Legal Domain", Law and Philosophy, 29, 2010, págs. 610-614. 
Un poco de realismo sobre inconstitucionalidad y derogación

reglas de inferencias podría conllevar consecuencias lógicamente insatisfactorias). Claramente, esta es una postura anti-realista en el ámbito de la teoría del derecho, ya que rehúsa describir lo que de hecho ocurre en los sistemas jurídicos, sobre la base reconstrucciones conceptuales construidas artificialmente ${ }^{26}$.

\section{Derogación e invalidez constitucional}

En la parte final de su artículo, ORS proponen un profundizado y sugerente análisis de las posibles relaciones entre derogación y declaración de inconstitucionalidad. Comparto, en buena medida, sus resultados, de forma que no los discutiré aquí.

Sin embargo, me parece que ORS omiten subrayar un punto importante relativo a dichas relaciones ${ }^{27}$. En los sistemas jurídicos con control de constitucionalidad centralizado y con efectos erga omnes de las sentencias estimatorias, la derogación implícita por aplicación del principio lex posterior y la declaración de inconstitucionalidad por aplicación del principio lex superior pueden converger en el caso en que una norma sea, a la vez, superior y posterior respecto de otra norma. Es este un caso donde la dicotomía entre orden depurado y orden no depurado parece encontrar algún problema, ya que la norma que es criterio de "pureza" entra a formar parte de la secuencia de sistemas en un momento sucesivo a la norma cuya consistencia con ella debería establecerse. Lo que es importante subrayar aquí, no obstante, es que el modelo del orden depurado parece decantarse por la aplicación del criterio lex posterior - con expulsión inmediata de la norma más antigua y consecuente inexistencia $a b$ origine de cualquier conflicto

${ }^{26}$ Sin embargo, distinguen cuidadosamente entre cuestiones, por así decirlo, de "sociología del razonamiento jurídico" y cuestiones lógicas Ferrer Beltrán, J. y Rodríguez, J. L., "Sobre dinámica jurídica y jerarquías normativas: Algunas respuestas a los críticos", cit., págs. 118-119, aunque no extraigan de ello todas las repercusiones conceptuales que, en mi opinión, cabe derivar.

${ }^{27}$ Véanse, no obstante, las agudas reflexiones que, respecto de este punto, se encuentran, más recientemente, en Orunesu, C., Positivismo jurídico y sistemas constitucionales, Madrid, Marcial Pons, 2012, pág. 135 ss. 
normativo - mientras que el modelo del orden no depurado parecería sugerir la aplicación del criterio jerárquico, con eventual expulsión de la norma inferior sobre la base de una sentencia del órgano del control de constitucionalidad. En términos de reconstrucción de lo que normalmente pasa en los sistemas de control centralizado, no cabe duda de que el segundo modelo parece ser más adecuado que el primero. Efectivamente, como afirma correctamente Guastini,

cuando está en discusión una antinomia entre constitución y ley anterior a la constitución, doctrina y jurisprudencia parecen preferir decididamente [la aplicación del criterio jerárquico], de manera que una norma legislativa en conflicto con la constitución, pero anterior a esta, debe considerarse no simplemente derogada, sino inválida, por inconstitucionalidad sobreviniente. Con la relevante consecuencia que la antinomia entre constitución y ley anterior no la pueden resolver los jueces comunes (por otra parte con efectos circunscritos al caso en cuestión), sino solo el Tribunal Constitucional (cuyas sentencias estimatorias tienen efectos erga omnes) ${ }^{28}$.

\section{Conclusiones}

En las páginas precedentes, he criticado algunas de las tesis propuestas por ORS hace algunos años en unas importantes contribuciones publicadas en esta revista. Es de sobra decir que dichas contribuciones contienen muchas tesis que merecen ser compartidas, pero sobre ellas nada he dicho, ni diré, en esta sede.

Quiero concluir diciendo que allí donde nuestras ideas divergen, me parece que lo hacen porque mis amigos ORS no mantienen una sana actitud realista acerca de lo que ocurre en el mundo jurídico, sino que hacen prevalecer sus estipulaciones conceptuales (y sus preferencias ideológicas) sobre los hechos empíricos, de forma que sus propuestas sobre estos puntos, implícitamente, se tornan dogmáticas,

${ }^{28}$ Guastini, R., Interpretar y argumentar, Madrid, Centro de estudios políticos y constitucionales, 2014, pág. 129. 
Un poco de realismo sobre inconstitucionalidad y derogación

más que teórico-generales. Es decir, versan sobre cómo debe ser el derecho y no sobre cómo es.

\section{Bibliografía}

Alchourrón, C. E. y Bulygin, E. "Sobre el concepto de orden jurídico" (1976), en Alchourrón C. E. y Bulygin, E., Análisis lógico y derecho, Madrid, Centro de estudios constitucionales, 1991.

Bulygin, E., "Cognition and Interpretation of Law", en L. Gianformaggio y S. Paulson (eds.), Cognition and Interpretation of Law, Torino, Giappichelli, 1995.

Ferrer Beltrán, J. Ratti, G. B., "Validity and Defeasibility in the Legal Domain", Law and Philosophy, 29, 2010.

Ferrer Beltrán, J., Rodríguez, J. L., Jerarquías normativas y dinámica de los sistemas jurídicos, Madrid, Marcial Pons, 2011.

Ferrer Beltrán, J., Rodríguez, J. L., "Sobre dinámica jurídica y jerarquías normativas: Algunas réplicas a los críticos", Analisi e diritto, 2013.

Gambaro, A., Il diritto di proprietà, Milano, Giuffrè, 1995.

Guastini, R., "Cinco observaciones sobre validez y derogación", Discusiones, 2, 2001.

Guastini, R., Interpretar y argumentar, Madrid, Centro de estudios políticos y constitucionales, 2014.

Hart, H. L. A., The Concept of Law, Oxford, Clarendon, II ed., 1994.

Kelsen, H., Pure Theory of Law, Berkeley, University of California Press, 1967.

Kelsen, H., General Theory of Law and State, New Brunswick (NJ), Transaction, [1945] 2006.

Orunesu, C., Positivismo jurídico y sistemas constitucionales, Madrid, Marcial Pons, 2012.

Orunesu, C., Rodríguez, J. L. y Sucar, G., "Inconstitucionalidad y derogación", Discusiones, 2, 2001.

Orunesu, C., Rodríguez, J. L. y Sucar, G., "Reflexiones ulteriores sobre inconstitucionalidad y derogación", Discusiones, 2, 2001.

Perot, P., "Inconstitucionalidad, legalidad y orden jurídico", Discusiones, 2, 2001. 
Ratti, G. B., "Tres disyuntivas teóricas en la reconstrucción de los órdenes jurídicos", Analisi e diritto, 2013.

Rescigno, P., "La proprietà (dir. priv.)", en Enciclopedia del diritto, XXXVII, Milano, Giuffrè, 1998.

Ross, A., On Law and Justice, London, Stevens \& Sons, 1958.

Schmill, U., "Observaciones a Inconstitucionalidad y derogación", Discusiones, 2, 2001.

Troper, M., "Une théorie réaliste de la validité", Analisi e diritto, 2014.

Tur, R., "The Alternative Character of the Legal Norm: Kelsen as a Defeasibilist?", en L. Duarte D'Almeida, J. Gardner, L. Green (eds.), Kelsen Revisited. New Essays on the Pure Theory of Law, Oxford, Hart, 2013. 